\title{
Luteolin-induced apoptosis through activation of endoplasmic reticulum stress sensors in pheochromocytoma cells
}

\author{
KISANG KWON $^{1}$, YOUNG-SOOK KWON ${ }^{2}$, SEUNG-WHAN KIM ${ }^{3}$, \\ KWEON YU ${ }^{4}$, KYUNG-HO LEE ${ }^{5}$ and O-YU KWON ${ }^{6}$
}

\begin{abstract}
${ }^{1}$ Department of Biomedical Laboratory Science, College of Health and Welfare, Kyungwoon University, Gumi 39160; ${ }^{2}$ Department of Nursing, College of Tourism and Health, Joongbu University, Geumsan 32713; ${ }^{3}$ Department of Emergency Medicine, Chungnam National University Hospital, Daejeon 35015; ${ }^{4}$ Korea

Research Institute of Bioscience and Biotechnology, Daejeon 34141; Department of Biological Sciences, College of Bioscience and Biotechnology, Konkuk University, Seoul 05029; ${ }^{6}$ Department of Anatomy and Cell Biology, College of Medicine, Chungnam National University, Daejeon 35015, Republic of Korea
\end{abstract}

Received February 26, 2016; Accepted February 6, 2017

DOI: $10.3892 / \mathrm{mmr} .2017 .6582$

\begin{abstract}
Luteolin [2-(3,4-dihydroxyphenyl)-5,7-dihydroxy-4-chromenone] is an active flavonoid compound from Lonicera japonica (Caprifoliaceae). Luteolin inhibits tumor cell proliferation, inflammatory and oxidative stress better, when compared with other flavonoids. In the present study, it was demonstrated that luteolin induces typical apoptosis in PC12 cells (derived from a pheochromocytoma of the rat adrenal medulla) accompanied by DNA fragmentation and formation of apoptotic bodies. In addition, luteolin regulates expression of the endoplasmic reticulum (ER) chaperone binding immunoglobulin protein, activating ER stress sensors (eukaryotic initiation factor $2 \alpha$ phosphorylation and X-box binding protein $1 \mathrm{mRNA}$ splicing) and induced autophagy. The results indicated that luteolin induces the upregulation of the unfolded protein response pathway through the ER stress sensors, which helps as an influential regulator for the apoptosis pathway in $\mathrm{PC} 12$ cells. The results suggested that the understanding of the molecular mechanisms underlying luteolin-induced apoptosis may be useful in cancer therapeutics,
\end{abstract}

Correspondence to: Professor O-Yu Kwon, Department of Anatomy and Cell Biology, College of Medicine, Chungnam National University, 266 Munhwa-ro, Jung-gu, Daejeon 35015, Republic of Korea

E-mail: oykwon@cnu.ac.kr

Professor Kyung-Ho Lee, Department of Biological Sciences, College of Bioscience \& Biotechnology, Konkuk University, 120 Neungdong-ro, Gwangjin-gu, Seoul 05029, Republic of Korea E-mail:kyungho@konkuk.ac.kr

Key words: luteolin, apoptosis, endoplasmic reticulum stress, autophagy, PC12 cells chemoprevention and neurodegenerative diseases, such as Parkinson's disease and Alzheimer's disease.

\section{Introduction}

Cells maintain their numbers by dividing, repairing, growing and dying through the cell cycle under normal conditions. However, an abnormal recovery mechanism following damage to cells may result in cell death. These cells may be genetically modified, grow excessively and become a malfunctioning cell mass, or cancer $(1,2)$. Cancers are one of the most common conditions globally, with >1.5 million treated for cancer in 2010 , according to the US National Cancer Institute (Rockville, MD, USA). The South Korean National Cancer Information Center reported that $\sim 1$ in every 3 people will develop cancer at some point in their lifetime (3). The incidence of all patients with cancers was estimated to be 445.3/100,000 people in 2012 .

Cancer cells divide rapidly, proliferate and invade surrounding tissues and organs, which eventually malfunction and are destroyed. Because of these cancer cell characteristics, it is difficult to treat cancer by only killing cancer cells without side effects affecting normal cells. Cancer treatment is divided into chemotherapy, radiation therapy and surgery (4). Chemotherapy involves drugs that kill or weakens cancer cells directly, however it is expensive, and the courses are long in duration. Chemotherapy often causes a variety of side effects, such as excruciating pain, anemia, decreased numbers of white blood cells and platelets, vomiting, diarrhea, reproductive disorders and chronic fatigue $(5,6)$. Thus, new methods to improve the clinical response to cancer chemotherapy with drugs that have fewer or no side effects are required.

Flavonoids are secondary plant metabolites and are biologically active polyphenolic compounds $(7,8)$. Among the various types of flavonoids, luteolin (2-(3,4-dihydroxyphenyl)-5,7-dihydroxy-4-chromenone) is a flavone in many substances, including celery, broccoli, green pepper, parsley and thyme (9). Several cellular and molecular biology studies have demonstrated that luteolin may possess anticancer activities $(10,11)$. 
Luteolin has a strong inhibitory effect on the nuclear factor- $\kappa \mathrm{B}$ pathway, which is continuously active in cancer cells (12). Proliferation of many kinds of cancer cells has been previously inibited by luteolin, including lung (A549), colon (HCT116), liver (HepG2), breast (MCF7/6), tongue (SCC-4), cervix (HeLa) and leukemia (HL-60) cells (13-19). Nevertheless, inhibiting cancer cell proliferation is a block in the development of new anticancer agents, because the details of the molecular mechanism remain unclear. Therefore, the authors tested the rat PC12 adrenal medulla pheochromocytoma cell line, which characteristic of neuroblastic and eosinophilic cells, as a model to examine the induction of endoplasmic reticulum (ER) stress-mediated apoptosis.

The ER is a membrane-bound intercellular organelle where lipid biosynthesis, post-translational modification, folding, processing and trafficking of secreted and membrane-bound proteins occurs (20). ER molecular chaperones serve central roles, and the binding immunoglobulin protein $(\mathrm{BiP})$ is the most representative chaperone; therefore, it can be used as an ER stress marker. The cellular response to ER stress is called the unfolded protein response (UPR), in which three ER stress sensors, inositol requiring enzyme 1 (IRE1), PKR-like ER kinase (PERK) and activating transcription factor 6 (ATF6), are downstream components of ER chaperones (21-24). Although luteolin-induced ER stress has been reported, little is known about the mechanisms of luteolin-induced apoptosis. In the current study, PC12 cells were used to understand the molecular mechanism of luteolin-induced activation of the UPR pathway. The results hope to provide clues for the therapeutic effects of luteolin on apoptosis through ER stress.

\section{Materials and methods}

Cell culture. PC12 cells were purchased from American Type Culutre Collection (cat. no. CRL-1721; Manassas, VA, USA) and cultured on collagen-coated flasks in 85\% RPMI-1640 medium, supplemented with $25 \mathrm{mM}$ HEPES buffer, $10 \%$ heat-inactivated horse serum, $5 \%$ heat-inactivated fetal bovine serum, 2 mM L-glutamine, $1 \mathrm{mM}$ sodium pyruvate, $1 \mathrm{~g} / 1$ d-(+)-glucose, $25 \mu \mathrm{g} / \mathrm{ml}$ streptomycin and $25 \mathrm{U} / \mathrm{ml}$ penicillin (all Gibco; Thermo Fisher Scientific, Inc., Waltham, MA, USA). The cells were maintained in a humidified incubator at $37^{\circ} \mathrm{C}$ in a $5 \% \mathrm{CO}_{2}$ atmosphere, and the medium was changed every 2 days. The cells were rinsed with 1 X DPBS and detached with $0.25 \%$ trypsin/EDTA (both Gibco; Thermo Fisher Scientific, Inc.). After centrifugation at $1,000 \mathrm{x} \mathrm{g}$ for $5 \mathrm{~min}$, the cells were subcultured in $25 \mathrm{~cm}^{2}$ flasks using 1:2-1:4 subcultivation ratios and were photographed every $24 \mathrm{~h}$ with an inverted microscope. Cells were passaged twice weekly. The $80 \%$ confluent monolayer of PC12 cells was treated with luteolin at the indicated doses and times. Total RNA from cultured cells was extracted using an RNA isolation reagent (TRI-Reagent; Ambion; Thermo Fisher Scientific, Inc.) and measured using the Nanodrop 1000 spectrophotometer (Thermo Fisher Scientific, Inc., Wilmington, DE, USA). The resulting RNA was used for the following reverse transcription-quantitative polymerase chain reaction experiments.

MTT assay. Cell viability measurements by MTT assay. Growth and viability of PC12 cells were determined using
MTT from Sigma-Aldrich; Merck KGaA (Darmadst, Germany). The cells were seeded in 96-well plates (at 60 to $80 \%$ confluency) and treated with luteolin for 0 (control), 4 and $16 \mathrm{~h}$. MTT solution $(0.5 \mathrm{mg} / \mathrm{ml})$ was added to each well, and the plates were incubated for an additional $4 \mathrm{~h}$ at $37^{\circ} \mathrm{C}$. Following removal of the medium, the formazan crystals were solubilized in DMSO (Sigma-Aldrich; Merck KGaA). Color development was monitored at $595 \mathrm{~nm}$ with a reference wavelength of $650 \mathrm{~nm}$ using the Sunrise ${ }^{\mathrm{TM}}$ microplate reader (Tecan Trading AG, Männedorf, Switzerland).

Hoechst 33342 staining. Following treatment with luteolin, PC12 cells were incubated for 30 min with Hoechst 33342 (Molecular Probes; Thermo Fisher Scientific, Inc.) loading dye and washed three times in ice-cold 1X PBS. Following staining for $10 \mathrm{~min}$, the stained cells were monitored using a fluorescence microscope (Axio Scope A1; Zeiss GmbH, Jena, Germany) at $340 \mathrm{~nm}$.

DNA fragmentation assay. Cells were lysed in $100 \mu 110 \mathrm{mM}$ Tris- $\mathrm{HCl}$ buffer (pH 7.4) containing $10 \mathrm{mM}$ EDTA and $0.5 \%$ Triton X-100. Following centrifugation for $5 \mathrm{~min}$ at $16,000 \mathrm{x} \mathrm{g}$, the supernatant was treated with RNase A and proteinase $\mathrm{K}$ (Promega Corporation, Madison, WI, USA). Subsequently, $20 \mu \mathrm{l}$ of $5 \mathrm{M} \mathrm{NaCl}$ and $120 \mu \mathrm{l}$ isopropanol were added and kept on ice for $1 \mathrm{~h}$. Following centrifugation for $15 \mathrm{~min}$ at 16,000 x g, the DNA pellets were dissolved in $20 \mu \mathrm{l}$ TE buffer $(10 \mathrm{mM}$ Tris- $\mathrm{HCl}$ and $1 \mathrm{mM}$ EDTA). The DNA samples were loaded onto a $0.7 \%$ agarose gel and observed using a UV source after ethidium bromide (Sigma-Aldrich; Merck KGaA) staining.

Semiquantitative reverse transcription-polymerase chain reaction ( $R T-P C R)$. RT-PCR conditions included 30 cycles of the following: $94^{\circ} \mathrm{C}$ for $30 \mathrm{sec}, 58^{\circ} \mathrm{C}$ for $30 \mathrm{sec}$ and $72^{\circ} \mathrm{C}$ for $1 \mathrm{~min}$ (10 $\mathrm{min}$ in the final cycle) using the below primers with Taq DNA polymerase (Solgent Co., Ltd., Daejeon, Korea). The RT-PCR primers were supplied by Bioneer Corporation (Daejeon, Korea). All chemicals were purchased from Sigma-Aldrich; Merck KGaA. The RT-PCR primers are as follows: IRE1 forward, 5'-ACCACCAGTCCATCG CCATT-3' and reverse, 5'-CCACCCTGGACGGAAGTT TG-3'; ATF6 forward, 5'-CTAGGCCTGGAGGCCAGG TT-3' and reverse, 5'-ACCCTGGAGTATGCGGGTTT-3'; PERK forward, 5'-GGTCTGGTTCCTTGGTTTCA-3' and reverse, 5'-TTCGCTGGCTGTGTAACTTG-3'; BiP forward, 5'-AGTGGTGGCCACTAATGGAG-3' and reverse, 5'-TCT TTTGTCAGGGGTCGTTC-3'; $\beta$-actin forward, 5'-ACA TCAAATGGGGTGATGCT-3' and reverse, 5'-AGGAGA CAACCTGGTCCTCA-3'. The figure presented the results of a representative experiment from three experiments with different samples.

Western blot analysis. PC12 cells were scraped and lysed by adding SDS sample buffer [62.5 mM Tris-HCl (pH 6.8), 6\% (w/v) SDS, 30\% glycerol and 125 mM DTT. Protein concentration was determined as described previously (25). Protein $(15 \mu \mathrm{g})$ was separated by $10 \%$ SDS-PAGE gel electrophoresis. The proteins were transferred to a nitrocellulose membrane, and the membranes were blocked by the $5 \%$ skim milk in $0.1 \%$ TBST (TBS with $0.1 \%$ Tween-20) for $1 \mathrm{~h}$ at room temperature 

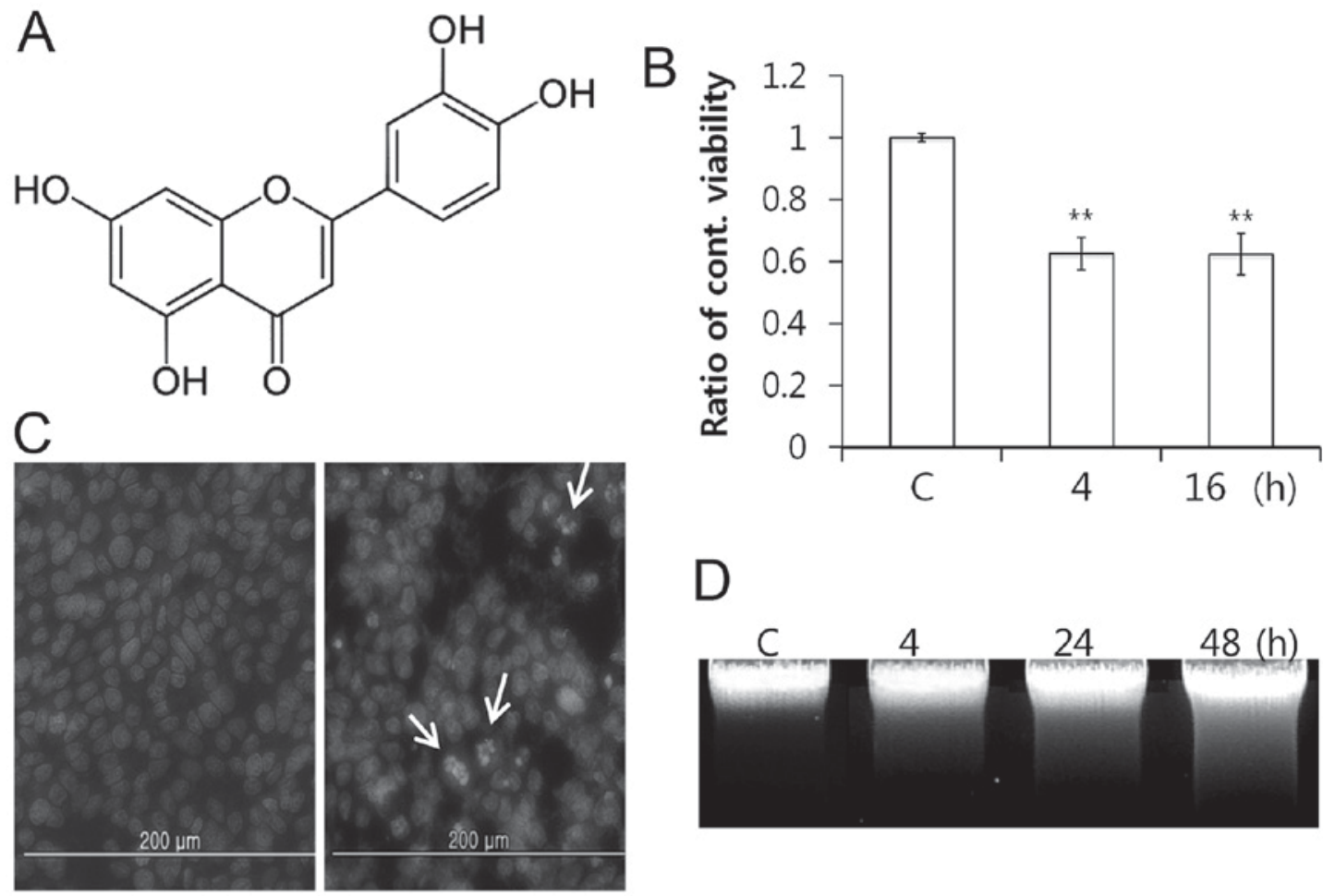

Figure 1. Luteolin induces apoptosis in PC12 cells. (A) The molecular structure of luteolin (chemical formula, $\mathrm{C}_{15} \mathrm{H}_{10} \mathrm{O}_{6}$; molar mass, $\left.286.24 \mathrm{~g} \cdot \mathrm{mol}^{-1}\right)$. (B) $\mathrm{PC} 12$ cells were treated with $100 \mu \mathrm{M}$ luteolin for 4 or $16 \mathrm{~h}$. Cell viability was measured by MTT assay. Data is presented as the mean \pm standard deviation. ${ }^{* *} \mathrm{P}<0.01$ vs. C (control). (C) The cells were treated with $100 \mu \mathrm{M}$ luteolin for $24 \mathrm{~h}$ and stained with Hoechst 33342 solution to detect formation of apoptotic bodies. Stained nuclei were observed under a fluorescent microscope using a blue filter. (D) To confirm DNA fragmentation, cells were treated with $100 \mu \mathrm{M}$ luteolin for 4,24 , and $48 \mathrm{~h}$. DNA was resolved on a $1.5 \%$ agarose gel and visualized with ethidium bromide.

and incubated with the primary antibodies (all 1:1,000 dilution) overnight at $4^{\circ} \mathrm{C}$. The rabbit anti-eIF $2 \alpha$ antibody (cat. no. sc-133132), eIF2 $\alpha-P$ antibody (cat. no. sc-133132p) and goat anti-actin antibody (cat. no. sc-1616-r) were obtained from Santa Cruz Biotechnology, Inc. (Dallas, TX, USA). The horseradish peroxidase-conjugated anti-rabbit (cat. no. sc-2004), anti-goat (cat. no. sc-2020) and anti-mouse (cat. no. sc-2005) IgG secondary antibodies were obtained from Santa Cruz Biotechnology, Inc. and were reacted with a 1:1,000 dilution for $1 \mathrm{~h}$ at room temperature. Goat anti-actin antibody was used to standardize the quantity of sample proteins. The mouse anti-ATF6 antibody (cat. no. NBP1-40256) was obtained from Novus Biologicals, LLC (Littleton, CO, USA). The blots were developed using an enhanced chemiluminescence western blotting detection system kit (Amersham; GE Healthcare Life Sciences, Chalfont, UK). Experiments were performed in triplicate and the protein bands were quantified using ImageJ software (version 1.48; https://imagej.nih.gov/ij/).

Statistical analysis. All statistical analyses were performed using the SPSS version 17.0 (SPSS, Inc., Chicago, IL, USA). Analysis of variance and Tukey-honest significant difference post hoc tests were performed to analyze the statistical significance. $\mathrm{P}<0.05$ was considered to indicate a statistically significant difference. Data are expressed as the mean \pm standard deviation, or as median values, in accordance with Gaussian distribution. All variables included in the regression analysis respected a linear distribution; when necessary, variables were linearized and checked for normality.

\section{Results and discussion}

Luteolin (Fig. 1A) is a flavone present in parsley, artichoke, celery and green pepper $(26,27)$. These plants have long been used in traditional medicine to treat a broad range of diseases. Luteolin inhibits growth of many cell types (28). The preliminary results using PC12 cells demonstrated morphological differences between luteolin-treated and control cells, as well as an increase in the number of floating cells in the medium (data not shown). This finding suggested that luteolin leads to cell death. The authors then tested the effects of $100 \mu \mathrm{M}$ luteolin on cell viability in the MTT assay following 4 and $16 \mathrm{~h}$ of treatment. Luteolin treatment inhibited the PC12 cell growth time-dependently, and luteolin-treated cell growth was reduced by half, following $4 \mathrm{~h}$ (Fig. 1B). This result suggested that apoptosis was induced based on cell shrinkage and extensive detachment of the cells (29). A total of two experiments were performed to determine whether luteolin induces chromatin condensation and DNA fragmentation, which are hallmarks of apoptosis. As a result, different nuclei were observed in cells treated with and without luteolin following Hoechst 33342 staining (Fig. 1C). Next, inter-nucleosomal DNA fragmentation increased time-dependently, which is the typical ladder pattern of apoptosis (Fig. 1D). These results indicated that luteolin-induced inhibition of cell growth is associated with induction of apoptosis in PC12 cells.

The UPR in mammalian cells comprises three separate ER stress sensors. These are downstream components of ER chaperones, which transmit stress signals from the ER to the 
A
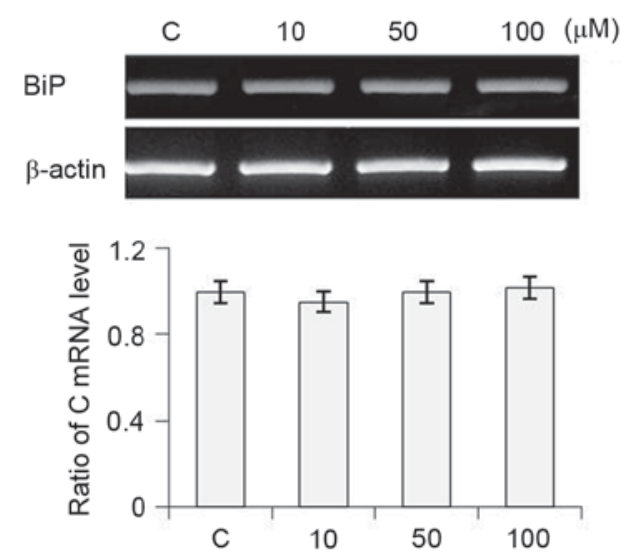

$\mathbf{C}$
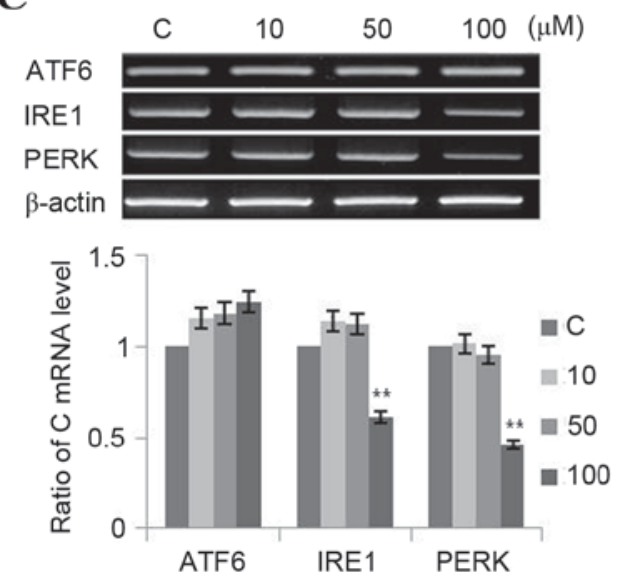

B

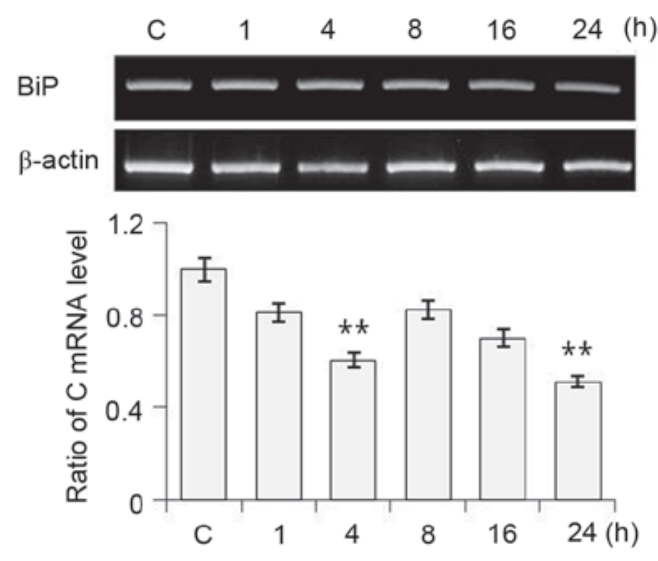

D
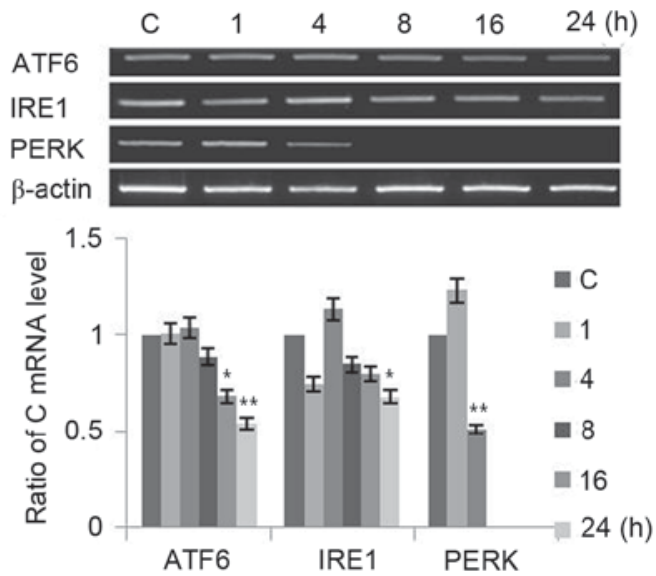

Figure 2. Expression of (A and B) ER chaperones and (C and D) ER stress sensors at different luteolin doses and times. PC12 cells were treated with luteolin $(10,50,100$ and $200 \mu \mathrm{M}$; panels A and C) for 1, 4, 8, 16 and $24 \mathrm{~h}$ (panels B and D). The revere transcription-polymerase chain reaction results were measured three times. Data is presented as the mean \pm standard deviation. ${ }^{*} \mathrm{P}<0.05$ and ${ }^{* *} \mathrm{P}<0.01$ vs. C (control). ER, endoplasmic reticulum; BiP, immunoglobulin heavy-chain binding protein; ATF6, activating transcription factor 6; IRE1, inositol-requiring kinase 1; PERK, PKR (protein kinase regulated by RNA)-like ER-associated kinase; C, control.

nucleus. IRE1 activates the endonuclease domains, which cleave X-box DNA-binding protein (XBP) mRNA, generating an activated form of the XBP1 protein (30). Activating PERK results in phosphorylation of the eIF $2 \alpha$ subunit and inhibits translation initiation (31). ATF6 is cleaved at the cytosolic face of the membrane in response to ER stress, and the resulting $\mathrm{N}$-terminal cytoplasmic domain subsequently binds to both the ER stress-response element and ATF6 sites, to enhance expression of ER molecular chaperone genes $(32,33)$. Binding immunoglobulin protein (BiP) binds transiently to newly synthesized proteins in the ER when a cell is ER stress-free. However, stimulating ER stress induces interactions with misfolded, underglycosylated and unassembled proteins through activation of ATF6, IRE1 and PERK (34). BiP eventually regulates the equilibrium between cell survival and apoptosis (35). Moreover, $\mathrm{BiP}$ is a principal regulator of ER stress signaling and survival in ER-stressed cells. ER stress-induced apoptosis is a key pathological event in various cancer cells $(36,37)$.

To understand whether luteolin-induced apoptosis is associated with ER stress, changes in the expression of $\mathrm{BiP}$ ATF6, IRE1 and PERK were evaluated under luteolin-treated conditions in PC12 cells. As presented in Fig. 2, treating PC12 cells with luteolin $(10,50$ and $100 \mu \mathrm{M})$ for $16 \mathrm{~h}$ altered $\mathrm{BiP}$ mRNA expression (Fig. 2A), and it decreased in response to $100 \mu \mathrm{M}$ luteolin following 1, 4, 8, 16 and $24 \mathrm{~h}$ of treatment (Fig. 2B). Expression of ATF6 and IRE1 tended to increase, whereas PERK expression decreased as luteolin concentration was increased (Fig. 2C). The expression of all of the ER stress sensors decreased over time reduced (Fig. 2D). In summary, luteolin downregulated transcription of $\mathrm{BiP}$ and the ER stress sensors gradually in a time-dependent manner, and upregulated ATF6 and IRE1 mRNA expression in a dose-dependent manner.

Furthermore, the authors investigated activation of the ER stress sensors in response to luteolin treatment, such as ATF6 fragmentation, eIF2- $\alpha$ phosphorylation and XBP1 mRNA splicing. Under ER stress conditions, ATF6 is transported from the ER to the Golgi complex, where it is sequentially cleaved by site 1 and site 2 proteases (38). An anti-ATF6-specific antibody that recognizes a $50 \mathrm{kDa}$ cleaved fragment form of ATF6 was used to understand activation of ATF6 under ER stress conditions. Upon ER stress, PERK phosphorylates eIF2- $\alpha$ 
A

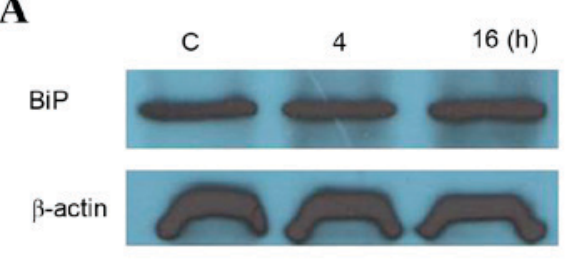

C

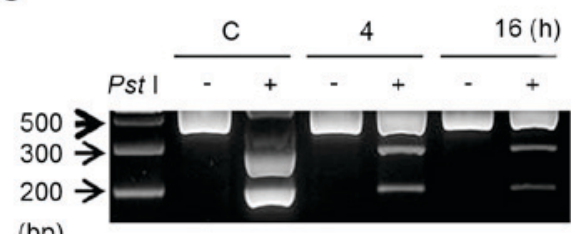

(bp)
B

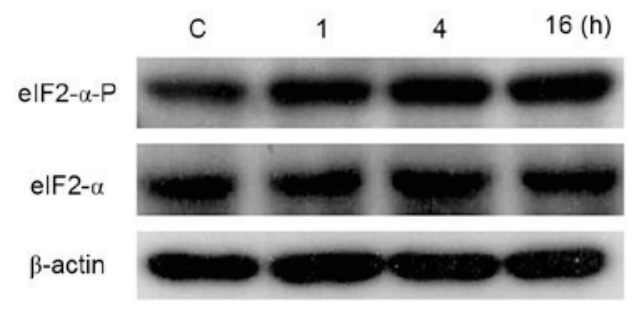

D

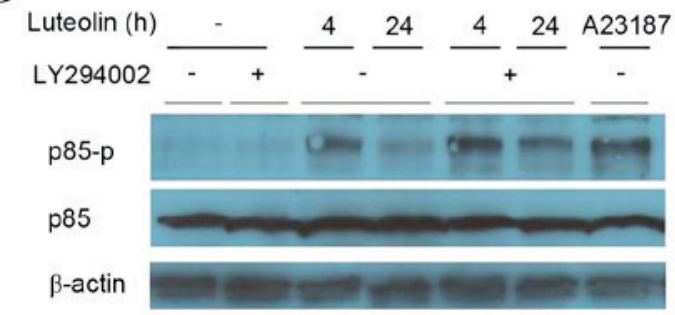

Figure 3. Luteolin controls endoplasmic reticulum stress sensors. (A) Cells were treated with $100 \mu \mathrm{M}$ luteolin for 4 and 16 h. Cell lysates were subjected to western blotting with mouse anti-ATF6 monoclonal antibody. (B) Western blotting was performed using anti-eIF2- $\alpha$ antibody and eIF2- $\alpha$-P antibody against cells treated for different times (1,4 and $16 \mathrm{~h}$ ). (C) The revere transcription-polymerase chain reaction analysis was performed using mRNAs from Fig. 3A. The resulting PCR product was further digested by Pst to reveal a restriction site that was lost following XBP1 splicing under ER stress. The resulting XBP1 cDNA products were revealed on a $2 \%$ agarose gel. Unspliced XBP1 mRNA produced the two lower bands indicated by arrows (upper, 290 bp and lower, $183 \mathrm{bp}$ ). The spliced XBP1 mRNA indicated by a bold arrow. (D) Western blotting was performed using a p85 antibody and p85-P antibody against cells treated for 4 and $24 \mathrm{~h}$. ATF6, activating transcription factor; eIF2-alpha, translation initiation factor eIF2- $\alpha$; eIF2-alpha-P, phosphorylated form of translation initiation factor eIF2 $\alpha$; XBP1, X-box binding protein 1; p85, phosphatidylinositol 3-kinase 85 kDa regulatory subunit alpha; p85-P, phosphorylated form of the phosphatidylinositol 3-kinase $85 \mathrm{kDa}$ regulatory subunit alpha; C, control.
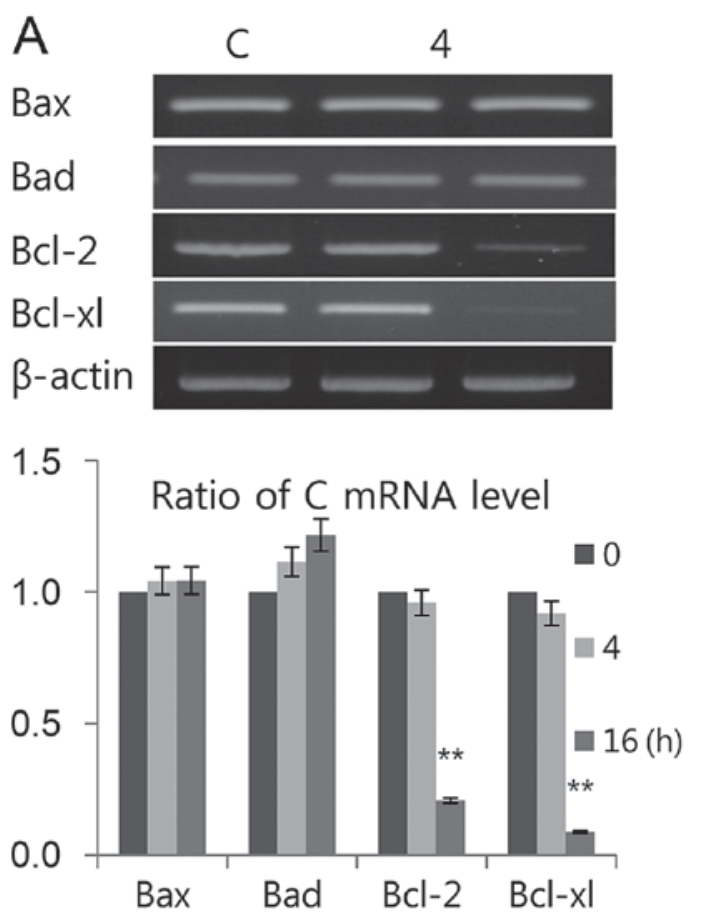
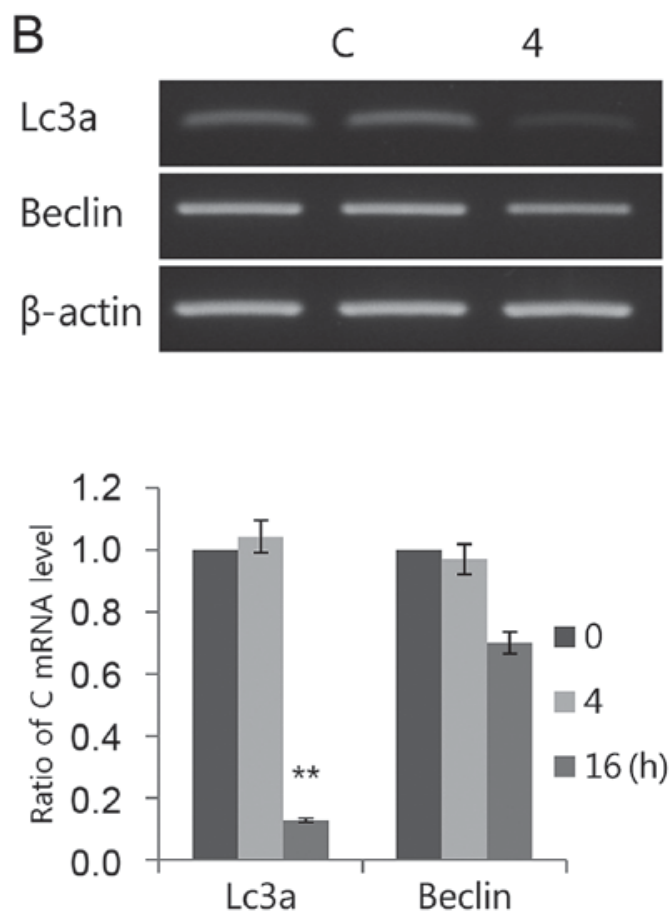

Figure 4. Luteolin induces (A) apoptosis and (B) autophagy. The mRNAs used for both tests were the same as those in Fig. 3A. Bax, Bad, mRNA levels of Bcl-2, Bcl-x1, LC3 and Beclin-1 were measured by RT-PCR. The RT-PCR results were measured three times. Data is presented as the mean \pm standard deviation. $\beta$-actin was used as the loading control. ${ }^{* *} \mathrm{P}<0.01$ vs. C (control). Bax, Bcl-2-associated X; Bad, Bcl-2-associated death promoter; Bcl-2, B-cell lymphoma 2; Bcl-xl, B-cell lymphoma/leukemia-x long; LC3, microtubule-associated protein light chain 3; Beclin-1, coiled-coil moesin-like BCL2 interacting protein; RT-PCR, semiquantitative revere transcription-polymerase chain reaction; $\mathrm{C}$, control.

to reduce biosynthesis of total mRNAs. Thus, we measured eIF2 $\alpha$ phosphorylation levels by western blotting to detect ER stress conditions. The ER stress-mediated splicing of XBP1 is a prerequisite for IRE1 activation, which controls the intensity of XBP1 splicing (removing a 26-bp segment from the full-length XBP-1 mRNA) (39). RT-PCR analysis was used to 
determine the unspliced and spliced isoforms of XBP1 mRNA. PC12 cells were treated with $100 \mu \mathrm{M}$ luteolin for 4 and $16 \mathrm{~h}$ (Fig. 3). Although luteolin did not induce ATF6 fragmentation (Fig. 3A), it gradually upregulated eIF2- $\alpha$ phosphorylation (Fig. 3B) and XBP1 mRNA splicing (Fig. 3C), suggesting that luteolin triggered the UPR signaling pathway by activating the ER stress sensors, except for ATF6. Phosphotidyl inositol 3-kinase (PI3 K) is a key regulator of many cellular processes, including cell survival, proliferation and differentiation (40). Under resting conditions, PI3K is composed of p85 and p110 (41). p85 interacts with other proteins (small GTPase cdc42, nuclear receptor co-repressor and CD148) that complex and serve significant roles in other cell signal pathways (42). Park et al (43) demonstrated that $\mathrm{p} 85$ interacts with the spliced form of XBP-1 (XBP-1s), which increases both XBP-1 s activity and the nuclear import of XBP-1s under ER stress conditions. Thus, the authors examined whether phosphorylation of $\mathrm{p} 85$ under ER stress conditions is related to luteolin stimulation. As demonstrated in Fig. 3D, short-term treatment $(4 \mathrm{~h})$ with luteolin induced higher levels of phosphorylated p85 than those of long-term treatment $(24 \mathrm{~h})$. The reason is unclear, but treatment with LY294002 upregulated phosphorylated p85. These data suggested that inhibition of PI3 K is associated with p85 phosphorylation through ER stress.

If early cellular responses fail to maintain ER homeostasis, ER stress activates the UPR to stimulate the apoptosis pathway for cell survival. The authors investigated whether luteolin induces both apoptosis and autophagy through the UPR, as the exact mechanisms of the induction of ER apoptosis and autophagy remain elusive. However, signaling through ER stress trigger several regulators associated with the apoptosis pathway during prolonged ER stress (44). A link between the UPR and autophagy has been presented; as phosphorylation of eIF $2 \alpha$ modulate autophagy and ER stress-inducible drugs induce autophagy (45). The present results indicated that luteolin induced transcriptional expression of pro-apoptotic Bax and Bad but decreased anti-apoptotic Bcl-2 and Bcl-xl (Fig. 4A). Luteolin strongly downregulated Lc3 and Beclin transcription levels (Fig. 4B), suggesting that luteolin upregulates apoptosis and downregulates autophagy in PC12 cells. In conclusion, although the underlying mechanism of luteolin in cell death is still unclear, the present study demonstrated luteolin regulates apoptosis and autophagy. Therefore, it may serve as a novel strategy to treat cancer by regulating the UPR signal.

In summary, luteolin treatment markedly induced apoptosis via the unfolded protein response, including ER chaperones and ER stress sensors, in PC12 cells. It is thought that further understanding of the biological mechanisms underlying luteolin-induced apoptosis may be useful in the prevention and treatment of chronic or acute neurological disorders such as Alzheimer's disease and Parkinson's disease as well as their symptoms (back pain) and signs (aphasia), and also neurological syndromes such as Aicardi syndrome.

\section{Acknowledgements}

The present study was supported by the research fund of Chungnam National University.

\section{References}

1. Sage EK, Thakrar RM and Janes SM: Genetically modified mesenchymal stromal cells in cancer therapy. Cytotherapy 18: 1435-1445, 2016.

2. Sharpe M and Mount N: Genetically modified T cells in cancer therapy: Opportunities and challenges. Dis Model Mech 8: 337-350, 2015.

3. Jung KW, Won YJ, Kong HJ, Oh CM, Cho H, Lee DH and Lee KH: Cancer statistics in korea: Incidence, mortality, survival, and prevalence in 2012. Cancer Res Treat 47: 127-141, 2015.

4. Runowicz CD, Leach CR, Henry NL, Henry KS, Mackey HT, Cowens-Alvarado RL, Cannady RS, Pratt-Chapman ML, Edge SB, Jacobs LA, et al: American cancer society/american society of clinical oncology breast cancer survivorship care guideline. J Clin Oncol 34: 611-635, 2016.

5. Overbeek A, van den Berg $\mathrm{MH}$, van Leeuwen FE, Kaspers GJ, Lambalk CB and van Dulmen-den Broeder E: Chemotherapy-related late adverse effects on ovarian function in female survivors of childhood and young adult cancer: A systematic review. Cancer Treat Rev 53: 10-24, 2017

6. Davoodi S, Mohammadzadeh Z and Safdari R: Mobile phone based system opportunities to home-based managing of chemotherapy side effects. Acta Inform Med 24: 193-196, 2016.

7. Crozier A, Burns J, Aziz AA, Stewart AJ, Rabiasz HS, Jenkins GI, Edwards CA and Lean ME: Antioxidant flavonols from fruits, vegetables and beverages: Measurements and bioavailability. Biol Res 33: 79-88, 2000.

8. López-Lázaro M: Distribution and biological activities of the flavonoid luteolin. Mini Rev Med Chem 9: 31-59, 2009.

9. Somerset SM and Johannot L: Dietary flavonoid sources in australian adults. Nutr Cancer 60: 442-449, 2008.

10. Lee YJ, Lim T, Han MS, Lee SH, Baek SH, Nan HY and Lee C: Anticancer effect of luteolin is mediated by downregulation of TAM receptor tyrosine kinases, but not interleukin-8, in non-small cell lung cancer cells. Oncol Rep 37: 1219-1226, 2017.

11. Yan H, Wei P, Song J, Jia X and Zhang Z: Enhanced anticancer activity in vitro and in vivo of luteolin incorporated into long-circulating micelles based on DSPE-PEG2000 and TPGS. J Pharm Pharmacol 68: 1290-1298, 2016.

12. Jia Z, Nallasamy P, Liu D, Shah H, Li JZ, Chitrakar R, Si H, McCormick J, Zhu H, Zhen W and Li Y: Luteolin protects against vascular inflammation in mice and tnf-alpha-induced monocyte adhesion to endothelial cells via suppressing IKB $\alpha / N F-\kappa B$ signaling pathway. J Nutr Biochem 26: 293-302, 2015.

13. Tang X, Wang H, Fan L, Wu X, Xin A, Ren H and Wang XJ: Luteolin inhibits Nrf2 leading to negative regulation of the Nrf2/ARE pathway and sensitization of human lung carcinoma A549 cells to therapeutic drugs. Free Radic Biol Med 50: 1599-1609, 2011

14. Shi RX, Ong CN and Shen HM: Luteolin sensitizes tumor necrosis factor-alpha-induced apoptosis in human tumor cells. Oncogene 23: 7712-7721, 2004.

15. Yee SB, Choi HJ, Chung SW, Park DH, Sung B, Chung HY and Kim ND: Growth inhibition of luteolin on hepG2 cells is induced via $\mathrm{p} 53$ and Fas/Fas-ligand besides the TGF- $\beta$ pathway. Int J Oncol 47: 747-754, 2015.

16. Attoub S, Hassan AH, Vanhoecke B, Iratni R, Takahashi T, Gaben AM, Bracke M, Awad S, John A, Kamalboor HA, et al: Inhibition of cell survival, invasion, tumor growth and histone deacetylase activity by the dietary flavonoid luteolin in human epithelioid cancer cells. Eur J Pharmacol 651: 18-25, 2011.

17. Yang SF, Yang WE, Chang HR, Chu SC and Hsieh YS: Luteolin induces apoptosis in oral squamous cancer cells. J Dent Res 87: 401-406, 2008

18. Tang L, Li Y, Chen WY, Zeng S, Dong LN, Peng XJ, Jiang W, $\mathrm{Hu} \mathrm{M}$ and Liu ZQ: Breast cancer resistance protein-mediated efflux of luteolin glucuronides in HeLa cells overexpressing UDP-glucuronosyltransferase 1A9. Pharm Res 31: 847-860, 2014.

19. Cheng AC, Huang TC, Lai CS, Kuo JM, Huang YT, Lo CY, Ho CT and Pan MH: Pyrrolidine dithiocarbamate inhibition of luteolin-induced apoptosis through up-regulated phosphorylation of Akt and caspase-9 in human leukemia HL-60 cells. J Agric Food Chem 54: 4215-4221, 2006.

20. Pereira DM, Valentão P, Correia-da-Silva G, Teixeira N and Andrade PB: Translating endoplasmic reticulum biology into the clinic: A role for ER-targeted natural products? Nat Prod Rep 32: 705-722, 2015. 
21. Zhang K and Kaufman RJ: From endoplasmic-reticulum stress to the inflammatory response. Nature 454: 455-462, 2008.

22. Rutkowski DT and Kaufman RJ: A trip to the ER: Coping with stress. Trends Cell Biol 14: 20-28, 2004.

23. Walter $P$ and Ron D: The unfolded protein response: From stress pathway to homeostatic regulation. Science 334: 1081-1086, 2011

24. Mori K: Signalling pathways in the unfolded protein response: Development from yeast to mammals. J Biochem 146: 743-750, 2009.

25. Noble JE: Quantification of protein concentration using UV absorbance and Coomassie dyes. Methods Enzymol 536: 17-26, 2014.

26. Lin LC, Pai YF and Tsai TH: Isolation of luteolin and luteolin-7-O-glucoside from dendranthema morifolium ramat Tzvel and their pharmacokinetics in rats. J Agric Food Chem 63 7700-7706, 2015.

27. Cai X, Lu W, Ye T, Lu M, Wang J, Huo J, Qian S, Wang X and Cao P: The molecular mechanism of luteolin-induced apoptosis is potentially related to inhibition of angiogenesis in human pancreatic carcinoma cells. Oncol Rep 28: 1353-1361, 2012.

28. Tuorkey MJ: Molecular targets of luteolin in cancer. Eur J Cancer Prev 25: 65-76, 2016.

29. Flusberg DA and Sorger PK: Surviving apoptosis: Life-death signaling in single cells. Trends Cell Biol 25: 446-458, 2015.

30. Chen L, Li Q, She T, Li H, Yue Y, Gao S, Yan T, Liu S, Ma J and Wang Y: IRE1 $\alpha$-XBP1 signaling pathway, a potential therapeutic target in multiple myeloma. Leuk Res 49: 7-12, 2016.

31. Axten JM: Protein kinase R (PKR)-like endoplasmic reticulum kinase (PERK) inhibitors: A patent review (2010-2015). Expert Opin Ther Pat 27: 37-48, 2017.

32. Kimata Y and Kohno K: Endoplasmic reticulum stress-sensing mechanisms in yeast and mammalian cells. Curr Opin Cell Biol 23: 135-142, 2011.

33. Welihinda AA, Tirasophon W and Kaufman RJ: The cellular response to protein misfolding in the endoplasmic reticulum. Gene Expr 7: 293-300, 1999.

34. Moreno JA and Tiffany-Castiglioni E: The chaperone Grp78 in protein folding disorders of the nervous system. Neurochem Res 40: 329-335, 2015.
35. Dandekar A, Mendez R and Zhang K: Cross talk between ER stress, oxidative stress, and inflammation in health and disease. Methods Mol Biol 1292: 205-214, 2015.

36. Breckenridge DG, Germain M, Mathai JP, Nguyen M and Shore GC: Regulation of apoptosis by endoplasmic reticulum pathways. Oncogene 22: 8608-8618, 2003.

37. Szegezdi E, Logue SE, Gorman AM and Samali A: Mediators of endoplasmic reticulum stress-induced apoptosis. EMBO Rep 7: 880-885, 2006

38. Clarke HJ, Chambers JE, Liniker E and Marciniak SJ: Endoplasmic reticulum stress in malignancy. Cancer Cell 25: 563-573, 2014

39. Martins AS, Alves I, Helguero L, Domingues MR and Neves BM: The unfolded protein response in homeostasis and modulation of mammalian immune cells. Int Rev Immunol 35: 457-476, 2016.

40. Vanhaesebroeck B, Stephens L and Hawkins P: PI3K signalling The path to discovery and understanding. Nat Rev Mol Cell Biol 13: 195-203, 2012.

41. Ohsaka Y and Nomura Y: Rat white adipocytes activate p85/p110 PI3K and induce PM GLUT4 in response to adrenoceptor agonists or aluminum fluoride. Physiol Int 103: 35-48, 2016.

42. Vogt PK, Hart JR, Gymnopoulos M, Jiang H, Kang S, Bader AG, Zhao L and Denley A: Phosphatidylinositol 3-kinase: The oncoprotein. Curr Top Microbiol Immunol 347: 79-104, 2010.

43. Park SW, Zhou Y, Lee J, Lu A, Sun C, Chung J, Ueki K and Ozcan U: The regulatory subunits of PI3K, p85alpha and p85beta, interact with XBP-1 and increase its nuclear translocation. Nature Med 16: 429-437, 2010.

44. Stefani IC, Wright D, Polizzi KM and Kontoravdi C: The role of ER stress-induced apoptosis in neurodegeneration. Curr Alzheimer Res 9: 373-387, 2012.

45. Lee WS, Yoo WH and Chae HJ: ER stress and autophagy. Curr Mol Med 15: 735-745, 2015. 